\section{Ladies among the guests}

DeAR SIRS

Â propos the interesting paper by Floate \& Williams (Psychiatric Bulletin, January 1991, 15, 28-30) describing the events leading to the admission in 1894 of the first woman member to the Medico-Psychological Association, readers may be further interested to know that it was not until 1920 that ladies, as guests, attended the Annual Dinner of the Association. The Journal of Mental Science (October 1920, 61, 496-497), reporting the 79th Annual Meeting of the Medico-Psychological Association, held at Stafford County Asylum, Cheddleton, states, "The Annual Dinner of the Association was held at $8.00 \mathrm{pm}$ on Wednesday July 28th, at the Palace Hotel, Buxton . . . Ladies were included among the guests and it is hoped that their presence may be an annual event in future".

University of Keele

E. D. MYERS

School of Postgraduate-Medicine and Biological Sciences

Stoke-on-Trent ST4 7QB

\section{Functional beds in old age}

DeAr SIRS

Parikh \& Stern (Psychiatric Bulletin, November $1990,14,657-660$ ) prompt us to report the findings of an audit of admissions to our unit for functional illness in old age (over 65) that highlighted similar points of interest regarding the factors that influence the duration of psychiatric admission.

During the 12 months of 1989-90, 102 patients were discharged, with mean age 75 and female:male ratio of 1.9:1. The mean duration of stay was 41 days but 16 admissions exceeded 10 weeks, meaning $16 \%$ of admissions occupied $38 \%$ of the total bed time. Comparing patients staying more or less than 10 weeks showed the longer stay group to be more likely to suffer psychotic depression $(P<0.05)$ and less likely to have a major depressive disorder without psychosis $(P<0.01)$ - a finding consistent with that of Baldwin (1988). They were also more likely to include admissions from medical wards $(P<0.05)$, less likely to be living with a spouse $(P<0.05)$, more likely to have poor or no family support $(P<0.001)$ and be discharged to residential care $(P<0.001)$.

Of the 16 longer stay group, six spent 196 days waiting for residential care after their treatment was completed, i.e. 33 days per patient. The importance of reducing admission time of longer stay patients has been demonstrated (Hirsch, 1983) but the urgency to discharge patients admitted for longer than 10 weeks declines rapidly (Hirsch et al, 1979). It is easy to become complacent while looking for residential placements for patients who have already spent sub- stantial time in treatment and make few demands on staff, yet this is clearly an area for saving bed time.

The audit data suggested other clinical areas for bed saving including intensive treatment and rehabilitation of physical and medical problems, use of newer psychotropic drugs with fewer adverse effects, and the earlier use of ECT for major depression.

Social variables like quality of community services, availability of residential care and family support need to be considered when determining requirements for functional beds in old age. The problem remains that of persuading managers that this type of data should be acknowledged and incorporated into decisions affecting service provision, and, though we commend audit as a mechanism to demonstrate areas for action, we are yet to be convinced that managers and administrators will respond to the information they are given.

\section{Fazakerley Hospital}

D. N. ANDERSON Liverpool L9 7AL

\section{References}

BALDWin, R. C. (1988) Delusional and non-delusional depression in late life. British Journal of Psychiatry, 152, 39-44.

HiRSCH, S. (1983) Bed requirements for acute psychiatric units - the concept of a norm. Bulletin of the Royal College of Psychiatrists, 7, 118-122.

- Platt, S., Knights, A. \& Weyman, A. (1979) Shortening hospital stay for psychiatric care: Effects on patients and their families. British Medical Journal, 1, 442-446.

\section{Community care of the elderly}

\section{DeAr Sirs}

Care in the community should be the provision of facilities for people in that community. It should not be the provision of people for facilities! A large influx of residents for speculatively developed care-homes would have adverse effects on existing services in that locality and be contrary to the College's Report (Psychiatric Bulletin, August 1987, 11, 278-282). The return of long-stay patients, or the migration of retired people to desirable areas, is reasonable. However, when wildly excessive care-home provision is developed in an area, residents have to be actively sought. The home's need, not the community's, may become paramount.

Current trends are worthy of note. Not only are some areas grossly over-provided (Psychiatric Bulletin, August 1990, 14, 460-461) but homes tend to conglomerate - a high percentage of buildings in one road or estate may be care homes. Such localities have been called 'ghettos" by our College and by local councillors who nevertheless cannot refuse 